\title{
Analysis of Soil Heavy Metal Hg Pollution Source Based on GeoDetector
}

\author{
Xvlu Wang, Yingjun Sun*, Han Guo, Huimeng Wang \\ College of Surveying and Mapping Geo-Informatics, Shandong Jianzhu University, Jinan, Shandong, China
}

Received: 11 March 2021

Accepted: 23 June 2021

\begin{abstract}
Heavy metal mercury $(\mathrm{Hg})$ is one of the most seriously polluted heavy metals in the soil of Liaocheng, China. But the source of $\mathrm{Hg}$ is still not clear. In this study, 85 soil samples were collected in the entire area of Liaocheng to obtain the spatial distribution of $\mathrm{Hg}$. The geological accumulation index was used to evaluate the pollution in the study area. The results showed that the average value of $\mathrm{Hg}$ exceeded the background value of Shandong Province, and in most areas of Liaocheng, $\mathrm{Hg}$ was in a light-medium pollution. In addition, the paper found obvious spatial heterogeneity of $\mathrm{Hg}$. So, the study area was divided into 2 parts according to the results of geological accumulation index - $\mathrm{I}_{\mathrm{geo}}$ : the lowvalue areas and high-value areas. They were also the two layers of dependent variable in the analysis of GeoDetector. It was used to find the source of heavy metal $\mathrm{Hg}$ pollution based on seven influencing factors: soil pH, soil organic matter, land use type, soil subcategory, GDP, distance from roads, and distance to water. Based on the results of the GeoDetector, the main factors affecting $\mathrm{Hg}$ in the $\mathrm{I}_{\text {geo }}$ lowvalue area were organic matter and soil type. Thus, the source of $\mathrm{Hg}$ in this area was mainly natural factors such as soil parent material. While in the $\mathrm{I}_{\text {geo }}$ high-value area, the paper found high-density and high-polluting industries with the Point of Interest data of factories and enterprises. It indicated that waste water, waste gas, waste residue generated in the production process of these industries were the main source of $\mathrm{Hg}$ pollution.
\end{abstract}

Keywords: GeoDetector, soil heavy metal Hg, impact factors, pollution source

\section{Introduction}

The destructiveness and irreversibility of heavy metals to soil have become one of the most serious problems of soil pollution $[1,2]$. In the past 30 years, with the rapid economic development, heavy metal pollution has become increasingly serious [3, 4]. Fuel combustion, automobile exhaust, production, and living

*e-mail: sdjzusyj@126.com emissions react in heavy metals accumulated in the soil, destroy the soil texture, soil degradation [5]. Heavy metals in soil are absorbed by plants, which will be harmful to human health [6-8]. Hg is one of the most toxic pollutants. High concentration of $\mathrm{Hg}$ will cause ecological damage [9]. Gaseous $\mathrm{Hg}$ pollutants have the characteristics of moving with the atmosphere. It can be transmitted over long distances, causing large-scale pollution [10]. Therefore, it is necessary to find the source of $\mathrm{Hg}$ pollution in the study region. Relevant research mainly used correlation analysis, 
principal component analysis [11], and multivariate statistical analysis [12] to identify pollution sources. These methods were more effective when there was a significant linear regression between variables. Therefore, this study used geographic detectors to detect the source of $\mathrm{Hg}$ pollution in the study area.

The geographical detector method (GeoDetector) can identify the spatial hierarchical heterogeneity and reveal the driving force behind the research object [13]. Geographic detectors can measure the correlation between the dependent variable and the independent variable in linear and nonlinear spatial distribution. The method has been applied in many fields. Gao et al. used geographic detectors to determine the influence of selected factors on the results of remote sensing ecological index models [14]. Yang et al. used geographic detectors to reveal the influencing factors and driving mechanism of the formation of rural settlement land pattern [15]. In addition, geographic detectors are widely used in related fields such as studies of the atmosphere [16-18], soil pollution [19-21], and urban economy [22].

This paper aimed to find the source of $\mathrm{Hg}$ pollution in the soil in Liaocheng City. GeoDetector was used to reveal the correlation between heavy metal $\mathrm{Hg}$ and factors such as soil $\mathrm{pH}$, soil organic matter, land use type, soil type, gross domestic product (GDP), distance from roads, and distance from water. It is important to identify the main factors affecting the sources of soil heavy metal pollution to provide a scientific basis for environmental protection and soil remediation in the study area [23-25].

\section{Materials and Methods}

\section{Study Area}

Liaocheng is in the western part of the Shandong Province, with Zhangwei River in the west, Jindi and Yellow Rivers in the southeast, and Jining, Tai'an, Jinan, Handan, and Dezhou adjacent to it. It is located at $115^{\circ} 16^{\prime}-116^{\circ} 12^{\prime} \mathrm{E}$ and $35^{\circ} 47^{\prime}-37^{\circ} 02^{\prime} \mathrm{N}$. The city has a total area of 8715 square kilometers, including eight counties.In2020, the city's GDP has reached 225.982 billion yuan. With rapid economic development, a series of environmental problems such as the deterioration of the environmental quality of scenic spots, water resource problems, and soil pollution followed [26].

\section{Materials}

The sampling points in the study area were designed in the center of $10 \mathrm{~km} \times 10 \mathrm{~km}$ grid (Fig. 1). After sampling, the soil samples were sent to the laboratory to extract the $\mathrm{Hg}$, the organic matter, soil type, soil $\mathrm{pH}$. The basic data used in the study included the 2015 GDP, the 2015-2016 Shandong Provincial Statistical Yearbook
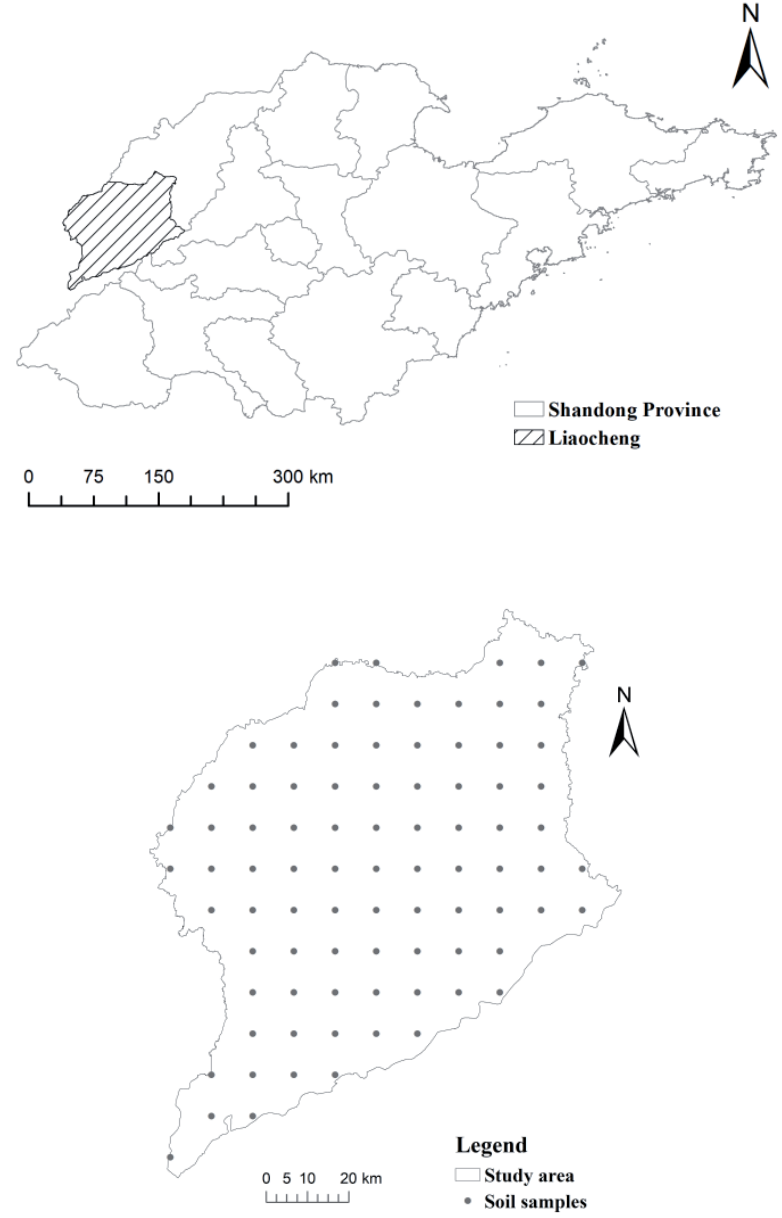

Fig. 1. Study area and location of sampling points.

(http://www.resdc.cn/), the third national land survey data, road data, and Point of Interest (POI) data. The POI data were obtained from the Baidu map database through python language programming. A total of 3854 location samples were imported into ArcGIS 10.3 for projection conversion. Several factors were selected for the study such as soil $\mathrm{pH}$, soil organic matter, land use type, soil subcategory, GDP, distance from roads, and distance to water. GDP was calculated through the 2015 GDP data and the 2015-2016 Shandong Provincial Statistical Yearbook; the distance from road and distance to water factors were found by calculating the Euclidean distance in ArcGIS 10.3.

\section{Methods}

\section{Geological Accumulation Index}

The geological accumulation index method [27] was first proposed by the German scientist Muller to evaluate the heavy metals in sediments. This method can not only distinguish the degree of human impact on the environment, but also reflects the natural distribution of heavy metals in the soil. The calculation formula is 
Table 1. Classification of pollution levels by geoaccumulation index.

\begin{tabular}{|c|c|c|}
\hline $\mathrm{I}_{\mathrm{geo}}$ & Level & Degree of pollution \\
\hline $\mathrm{I}_{\mathrm{geo}} \leq \mathbf{0}$ & 0 & No pollution \\
\hline $0<\mathrm{I}_{\mathrm{geo}} \leq \mathbf{1}$ & 1 & Mild to moderate pollution \\
\hline $1<\mathrm{I}_{\mathrm{geo}} \leq \mathbf{2}$ & 2 & Moderate pollution \\
\hline $2<\mathrm{I}_{\mathrm{geo}} \leq \mathbf{3}$ & 3 & Moderate to heavy pollution \\
\hline
\end{tabular}

$$
\mathrm{I}_{\text {geo }}=\log _{2}\left[\mathrm{C}_{\mathrm{n}} /\left(\mathrm{k} \times \mathrm{C}_{\mathrm{i}}\right)\right]
$$

...where $\mathrm{I}_{\text {geo }}$ is the geological accumulation index of soil heavy metals; $\mathrm{C}_{\mathrm{n}}$ is the measured value of soil heavy metals in $\mathrm{mg} / \mathrm{kg} ; \mathrm{C}_{\mathrm{i}}$ is the soil background value of heavy metals in the study area; and $\mathrm{k}$ is used to correct the irregularities in the background value of soil heavy metals that may be caused by sedimentation (generally $\mathrm{k}=1.5$ ). In addition, the potential ecological risk index is used to support the results of the geological accumulation index, as detailed in Hakanson's literature [28]. The pollution level can be divided according to the geological accumulation index (see Table 1).

\section{Geographical Detector}

The Geodetector is a model proposed by researcher Wang Jinfeng to analyze the heterogeneity of spatial stratification. The model is divided into 4 modules: factor detection, risk detection, ecological detection, and interaction detection.

Factor detection is used to detect the spatial hierarchical heterogeneity of variable $\mathrm{Y}$, and the extent to which impact factor $\mathrm{X}$ explains the spatial differentiation of variable $\mathrm{Y}$, which is measured by the q value $[29,30]$. In this study, the factor detector is used to analyze the correlation between the selected impact factors and heavy metal $\mathrm{Hg}$, to analyze the attribution of the pollution source. The calculation formula is

$$
\mathrm{q}=1-\frac{\sum_{\mathrm{i}=1}^{\mathrm{L}} \mathrm{N}_{\mathrm{i}} \sigma_{\mathrm{i}}^{2}}{\mathrm{~N} \sigma^{2}}=1-\frac{\mathrm{SSW}}{\mathrm{SST}}
$$

...where $\mathrm{i}=1, \ldots, \mathrm{L}$ is the division or classification of factor $\mathrm{X}$ or variable $\mathrm{Y} ; \mathrm{N}_{\mathrm{i}}$ and $\mathrm{N}$ are the number of units in layer $\mathrm{i}$ and the whole area, respectively; and are the variance of variable $\mathrm{Y}$ in layer $\mathrm{i}$ and the whole area, respectively; and $\mathrm{SSW}=$ and $\mathrm{SST}=$ indicate the sum of variance within the layer and the total variance of the whole area, respectively.

\section{Results}

\section{Statistical Analysis}

The statistical description of $\mathrm{Hg}$ is shown in Table 2. Radial basis function [31] was used to obtain the spatial
Table 2. Statistical description parameters of $\mathrm{Hg}$.

\begin{tabular}{|c|c|}
\hline Parameters & Result \\
\hline Mean value $(\mathrm{mg} / \mathrm{kg})$ & 0.042 \\
\hline Range $(\mathrm{mg} / \mathrm{kg})$ & $0.008-1.635$ \\
\hline Skewness & 25.668 \\
\hline Kurtosis & 905.95 \\
\hline Coefficient of Variation & 1.024 \\
\hline $\begin{array}{c}\text { Background values for Shandong Province } \\
(\mathrm{mg} / \mathrm{kg})\end{array}$ & 0.019 \\
\hline National Level II Standards $(\mathrm{mg} / \mathrm{kg})$ & 0.5 \\
\hline
\end{tabular}

distribution of $\mathrm{Hg}$ (Fig. 2). The root mean square error of the model was 0.036 . The average value of $\mathrm{Hg}$ was $0.042 \mathrm{mg} / \mathrm{kg}$, which was 2.21 times the background value in Shandong; the maximum value was $1.635 \mathrm{mg} / \mathrm{kg}$, which was 86 times the background value in Shandong and 3.27 times the national secondary standard, indicating that the concentration of $\mathrm{Hg}$ in the study area was abnormal. The area with a higher concentration than the national secondary standard had been polluted by $\mathrm{Hg}$, which could damage the ecological environment. It could be seen from the skewness and kurtosis that the $\mathrm{Hg}$ did not conform to the normal distribution, and its coefficient of variation was much higher than 0.36 [32], indicating that the distribution of heavy metal $\mathrm{Hg}$ was highly variable and the soil in the study area was likely subject to human disturbance. In addition, it can be seen from Fig. 2 that the $\mathrm{Hg}$ was distributed

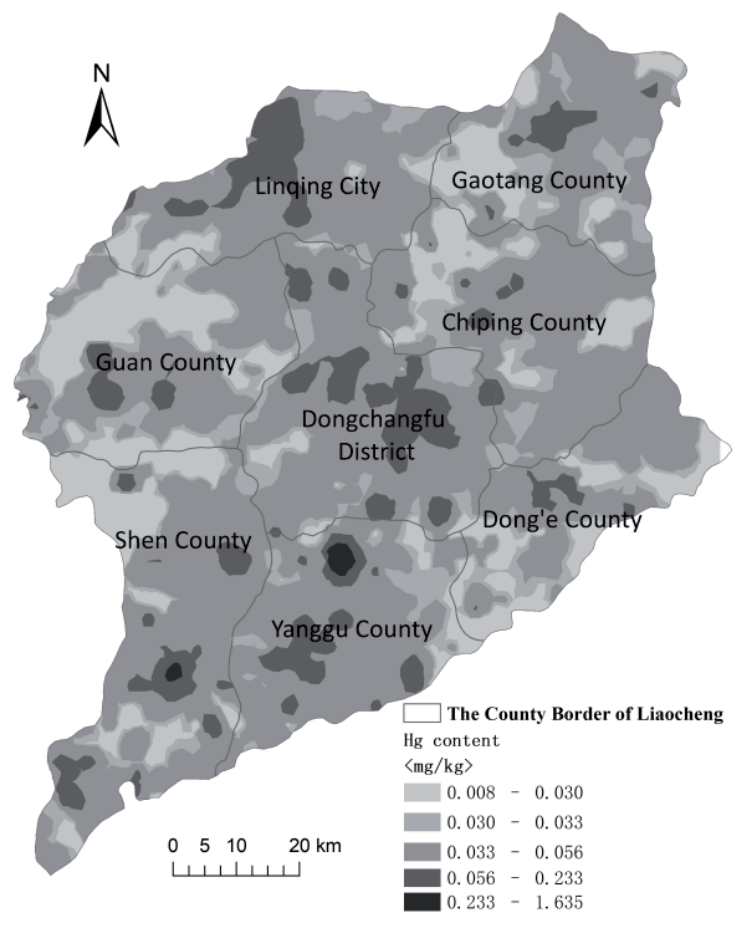

Fig. 2. Spatial distribution of heavy metal Hg. 


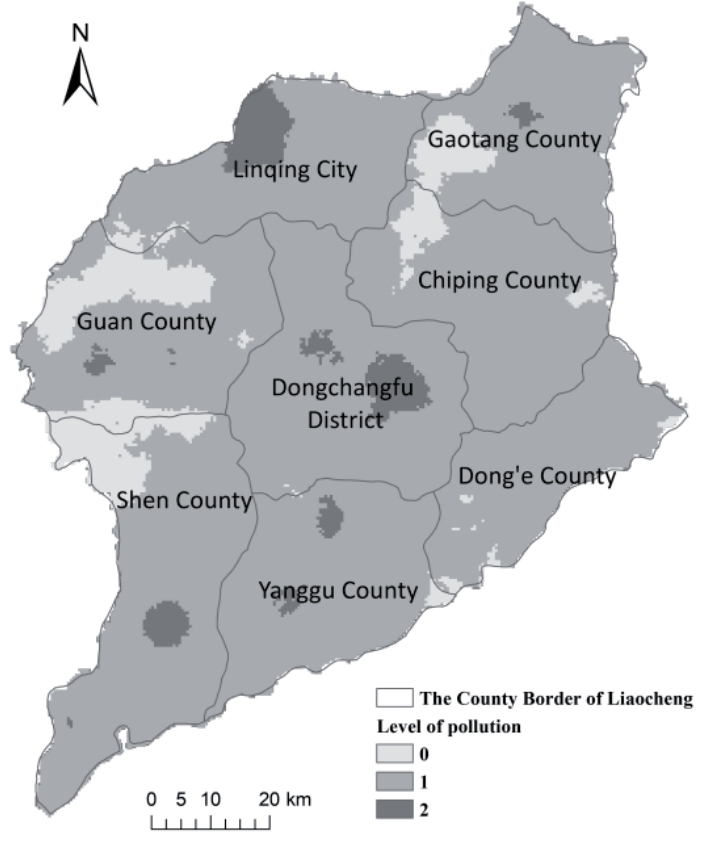

(a) Geoaccumulation index

Fig. 3. Spatial distribution of heavy metal mercury pollution.

in various counties and cities throughout Liaocheng, and concentrated in Linqing, Dongchangfu District, Yanggu, and Shen County.

\section{Analysis of Pollution Index}

The Hg pollution in the study area was evaluated according to the Geoaccumulation index (Fig. 3a). In most areas of Liaocheng, $\mathrm{Hg}$ was found in a lightmedium pollution concentration. The areas most heavily polluted by $\mathrm{Hg}$ were concentrated in Linqing, Dongchangfu District, and Shen County. To verify the result of the geoaccumulation index, this study used the potential ecological risk index method to evaluate the $\mathrm{Hg}$ pollution in the area. The potential ecological risk index of heavy metal mercury $<40$ is mild risk, $40-80$ is medium risk, $80-160$ is medium-high risk, $160-320$ is high risk, $\geqq 320$ is highest risk. The results are shown in Fig. 3b). As shown, most areas of Liaocheng were at higher risk. The higher risks were mainly distributed in Linqing, Dongchangfu District, Yanggu County, and Shen County, which were found to have similar levels of $\mathrm{Hg}$ concentration as the heavily polluted areas evaluated by the geoaccumulation index.

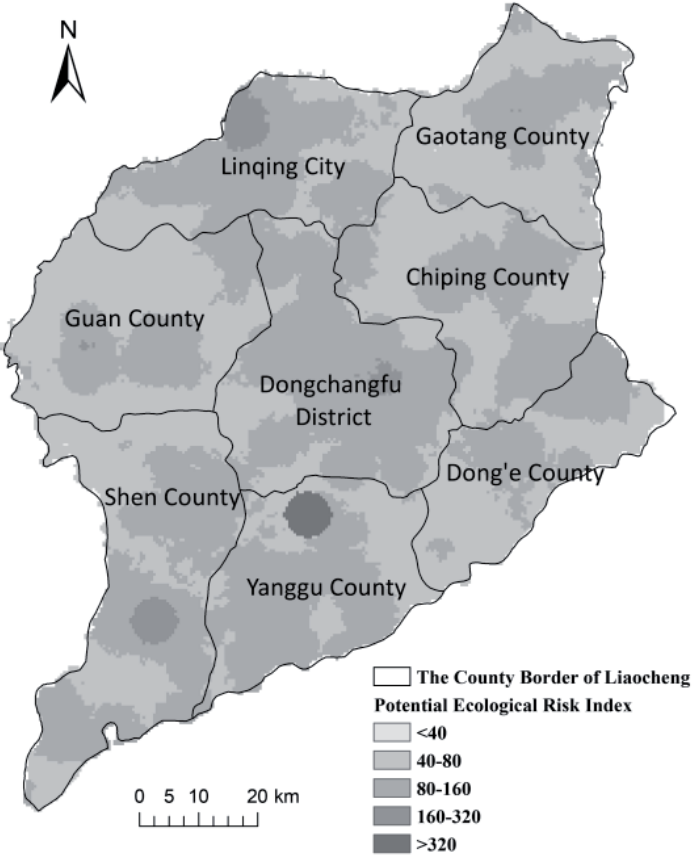

(b) Potential ecological risk

\section{Geodetector Analysis}

Because the data used by the geodetector software (http://geodetector.cn/) in the calculation process were type data rather than continuous data, the dependent variable needed to be discretized. This study used the natural breakpoint method and K-means [33] as the two methods to classify the data (Table 3). The spatial distribution of each factor classification is shown in Fig. 4.

After detecting the concentration and distribution of heavy metal $\mathrm{Hg}$ in the soil of Liaocheng (Table 4), the $\mathrm{q}$ value was found to be relatively small. Based on the results of geological accumulation, the study was divided into two layers. The first layer was called the $I_{\text {geo }}$ low-value area, or the area where the geological accumulation index level was 0 and 1 . Then, the second layer was called the $\mathrm{I}_{\mathrm{geo}}$ high-value area, or the area where the geological accumulation index level was 2 .

\section{Pollution Analysis of $I_{g e o}$ Low-Value Area}

The research was divided into two layers and then the factor detection was performed on each layer.

Table 3. Factor classification.

\begin{tabular}{|c|c|c|c|}
\hline Impact factors & Organic matter & Distance from road & Distance to river \\
\hline Natural breakpoint & 7 & 5 & 7 \\
\hline Impact factors & $\mathrm{pH}$ & GDP & \\
\hline K-means & 9 & 9 & \\
\hline
\end{tabular}




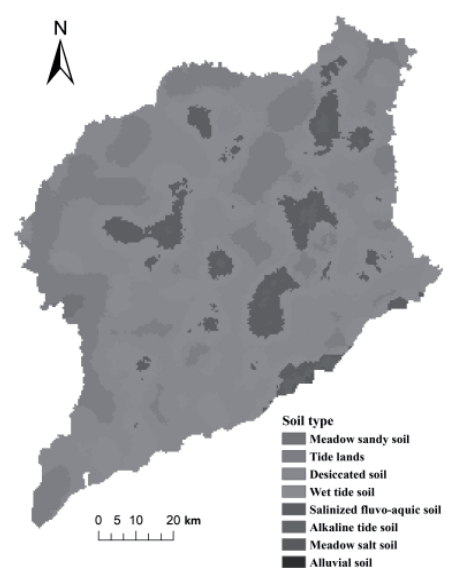

(a) Soil subcategory

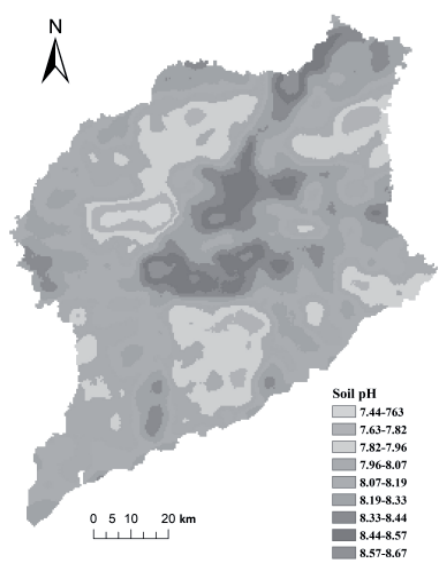

(c) Soil pH

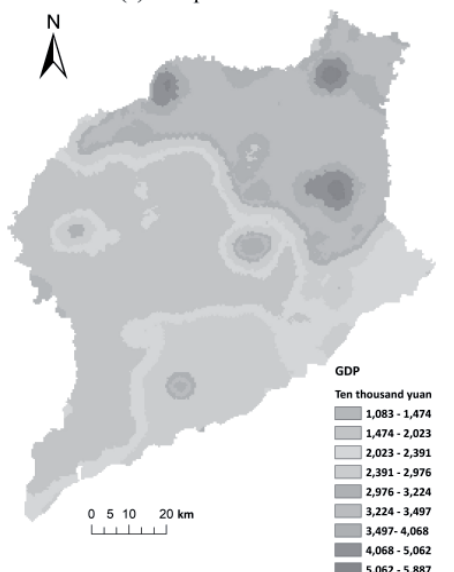

(e) GDP

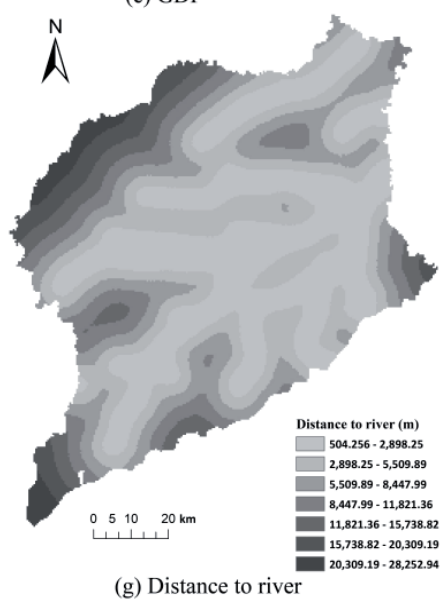

(g) Distance to river

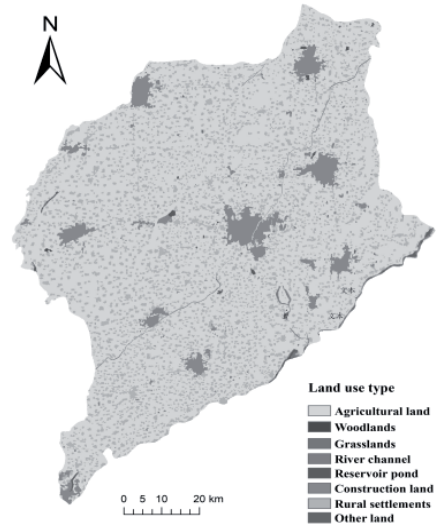

(b) Land use

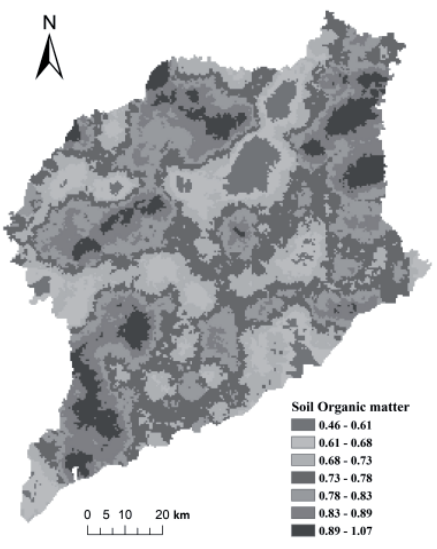

(d) Soil Organic matter

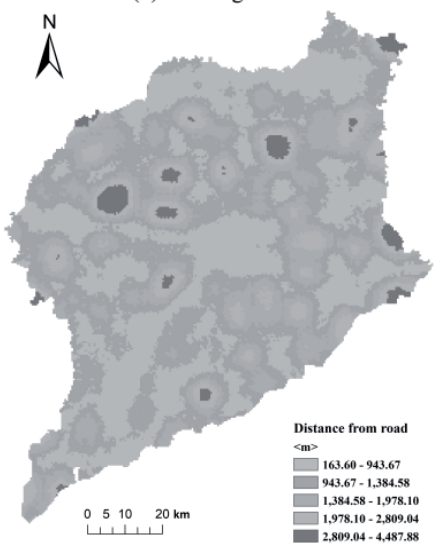

(f) Distance from road

Fig. 4. Spatial distribution of various impact factors. 
Table 4. Factor detection results.

\begin{tabular}{|c|c|c|c|c|c|c|c|}
\hline Factors & Organic matter & Soil type & Soil $\mathrm{pH}$ & Land use type & Distance to water & Distance from road & GDP \\
\hline $\mathrm{q}$ & 0.030 & 0.009 & 0.005 & 0.010 & 0.003 & 0.005 & 0.010 \\
\hline
\end{tabular}

Table 5. Factor detection results of $\mathrm{I}_{\text {geo }}$ low-value area.

\begin{tabular}{|c|c|c|c|c|c|c|c|}
\hline Factors & Organic matter & Soil type & Soil $\mathrm{pH}$ & Land use type & Distance to water & Distance from road & GDP \\
\hline $\mathrm{q}$ & 0.160 & 0.064 & 0.015 & 0.026 & 0.010 & 0.014 & 0.026 \\
\hline
\end{tabular}

The result of the $\mathrm{I}_{\text {geo }}$ low-value area is shown in Table 5. The impact factors were sorted according to the q value as follows: organic matter $(0.160)>$ soil type $(0.064)>$ GDP $(0.026)=$ land use type $(0.26)>\mathrm{pH} \quad(0.015)>$ distance from road $(0.014)>$ distance to river $(0.01)$. According to the results of factor detection, organic matter and soil type were the two factors most closely related to $\mathrm{Hg}$ in the $\mathrm{I}_{\text {geo }}$ low-value areas. The aforementioned two factors are natural factors, indicating that the concentration of $\mathrm{Hg}$ in the low-value area was mainly affected by natural factors such as soil parent material and weathering. In addition, due to the volatility of $\mathrm{Hg}$ and its compounds [34], Hg pollutants would diffuse through the air from the pollution source to the surrounding areas. In the $\mathrm{I}_{\text {geo }}$ low-value area, the main soil subcategory was fluvo-aquic soil, which has a viscous texture and high $\mathrm{pH}$, making it easy to adsorb pollutants. Therefore, as shown in Fig. 3a), the moderately polluted area was surrounded by light-medium polluted areas, and only a type few non-polluted areas were found, and they were far from the moderately polluted areas.

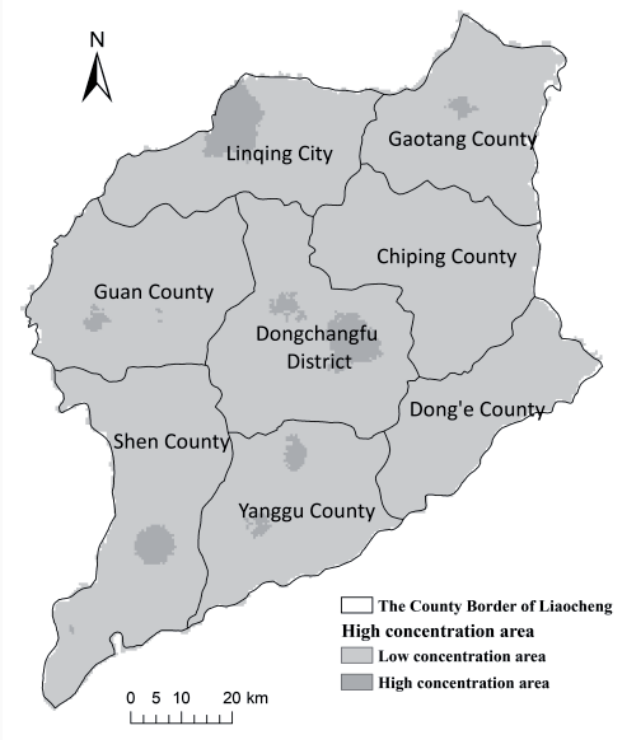

(a) Spatial distribution of high and low concentration areas

\section{Pollution Analysis of $I_{\text {geo }}$ High-Value Area}

For the $\mathrm{I}_{\text {geo }}$ high-value area, the $\mathrm{q}$ value of the impact factor was between 0.009 and 0.034 . This might be due to the poor explanatory power of the obtained data for the distribution of heavy metal $\mathrm{Hg}$ in the $\mathrm{I}_{\mathrm{geo}}$ highvalue area. Combined with Fig. 4b) and 4e), this region had a large area of urban land, and the high GDP was concentrated in these areas. The area was economically developed and was greatly affected by human activities. Thus, the source of heavy metal $\mathrm{Hg}$ in the $\mathrm{I}_{\text {geo }}$ highvalue area was analyzed directly from the location of the public enterprise.

This study used the POI data of factories and enterprises in Liaocheng and classified the POI data of various factories and enterprises using the introduction of the Liaocheng People's Government Economic and Social Development Statistical Bulletin (http://www. liaocheng.gov.cn/lcsq/jjsh/). The result is shown in Fig. 5. In the $I_{\text {geo }}$ high-value area, the density of factories and enterprises was very high. These factories and enterprises were mainly textile printing and

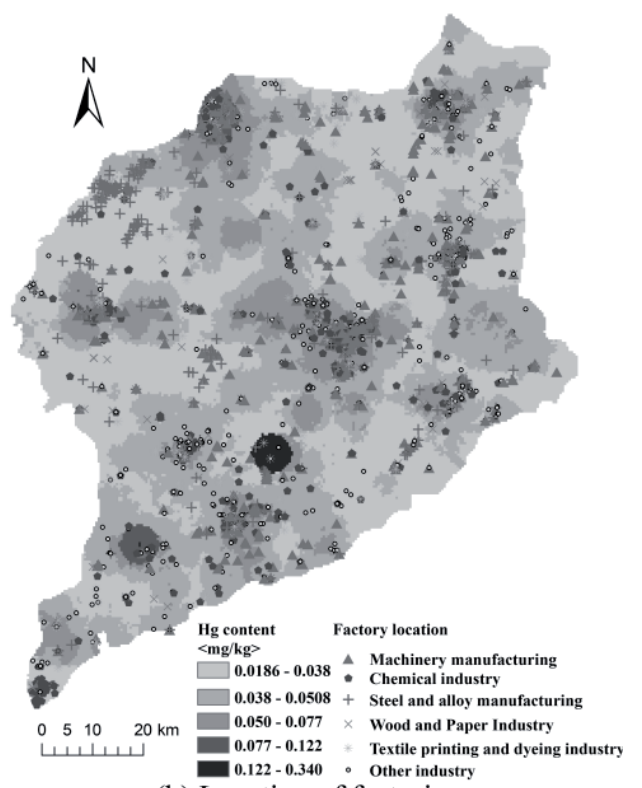

(b) Location of factories

Fig. 5. Spatial distribution of industrial enterprises 
dyeing, machinery manufacturing, various non-ferrous metal alloy manufacturing, chemical industry, and papermaking. These enterprises are in highly polluting industries [35]. Among them, the textile and paper industries used heavy metal $\mathrm{Hg}$ as the flowing cathode chlor-alkali process during production, resulting in extremely high levels of pollutant $\mathrm{Hg}$ emissions [36]. Machinery manufacturing, metal smelting, and chemical industry discharged the "three wastes" containing a large amount of heavy metals in the production process.

\section{Discussion}

The concentration of the heavy metal $\mathrm{Hg}$ in the soil of the study area ranged from 0.008 to $1.635 \mathrm{mg} / \mathrm{kg}$, with an average value of $0.042 \mathrm{mg} / \mathrm{kg}$, which was about twice the Shandong background value. The maximum value far exceeded the national secondary standard, indicating that the soil samples at individual sampling points exceeded the standard, causing damage to the local ecology. In addition, the coefficient of variation of the concentration of $\mathrm{Hg}$ was 1.024, indicating that $\mathrm{Hg}$ had accumulated in the study area, mainly in Linqing, Dongchangfu District, Yanggu County, and Shen County. Through the pollution index analysis, it was found that heavy metal $\mathrm{Hg}$ was seriously polluted in Linqing, Dongchangfu District, Yanggu County, and Shen County. These areas were the economically developed and urbanized regions in the study area, indicating that these areas were heavily influenced by humans. The study was divided into two layers according to the results of the geoaccumulation index: $\mathrm{I}_{\text {geo }}$ low-value area and $\mathrm{I}_{\text {geo }}$ high-value area. The selected seven impact factors were separated from the $\mathrm{Hg}$ for factor detection.

In the $\mathrm{I}_{\text {geo }}$ low-value areas, factor detection analysis showed that $\mathrm{Hg}$ was mainly affected by two natural factors, organic matter and soil type. In addition to these two natural factors, GDP and land use types also had an impact on the distribution of $\mathrm{Hg}$. These two factors reflect economic development and the intensity of human activities. Hg shown in Fig. 4b) and 4e), the GDP in the $\mathrm{I}_{\text {geo }}$ low-value area was at a medium level, and farmland was the main land use type in this area. There was no large area of urban land in this region, but there were densely distributed rural settlements, indicating that in addition to natural factors, wastewater and waste gas generated by local residents' production, life, and agricultural activities were also sources of $\mathrm{Hg}$. In addition, even though soil $\mathrm{pH}$, distance from roads, and distance from rivers had a certain impact on $\mathrm{Hg}$, the impact was relatively small. According to the above analysis, the heavy metal $\mathrm{Hg}$ found in the $\mathrm{I}_{\text {geo }}$ low-value area was mainly from natural factors such as soil parent material. Due to the volatile nature of $\mathrm{Hg}$ and the characteristics of the local economy and land use, the heavy metal $\mathrm{Hg}$ in these areas was affected by the proliferation of pollution sources from the $\mathrm{I}_{\text {geo }}$ high-value area. At the same time, the dense rural settlements and frequent agricultural activities in this area also had an impact on the heavy metal $\mathrm{Hg}$ distribution.

In the $I_{\text {geo }}$ high-value area, through POI data analysis, $\mathrm{Hg}$ was mainly affected by the three industrial wastes. $\mathrm{Hg}$ and its compounds were very volatile, allowing them to be transported over long distances through the atmosphere. Approximately 93.7\% of $\mathrm{Hg}$ can fall back to land [37]. Hence, soil was the largest pollutant receiver of heavy metal $\mathrm{Hg}$. In addition, as shown in Fig. 5b), areas with high $\mathrm{Hg}$ concentrations overlapped with $\mathrm{I}_{\text {geo }}$ high-value areas. The trends of the concentration level of $\mathrm{Hg}$ were basically the same as that of high-polluting industries. The above analysis showed that these high-polluting industries were the main source of heavy metal $\mathrm{Hg}$ pollution in the region, and these areas were mostly the central urban areas of counties and cities. Thus, it is necessary to pay attention to the pollution to prevent damage to the ecological environment of the region and the health of residents. This article had limitations in factor selection and there were few socioeconomic factors, so relevant factors should be added to continue research.

\section{Conclusions}

According to statistical analysis and pollution evaluation, $\mathrm{Hg}$ pollution existed in Liaocheng. In order to detect the source of $\mathrm{Hg}$ pollution, the study area was divided into the $\mathrm{I}_{\text {geo }}$ low-value area and the $\mathrm{I}_{\text {geo }}$ high-value area based on the results of geological accumulation. In the $I_{\text {geo }}$ low-value area, the $q$ values of organic matter and soil type were 0.16 and 0.064 , respectively. This indicated that the main source of heavy metal $\mathrm{Hg}$ in the $I_{\text {geo }}$ low-value area was soil parent material and other natural factors. However, due to the volatility of $\mathrm{Hg}$ and the local economic and land use conditions, the $\mathrm{Hg}$ in this area was also affected by the diffusion of $\mathrm{Hg}$ in the $\mathrm{I}_{\text {geo }}$ high-value area and local human activities. For the $\mathrm{I}_{\text {geo }}$ high-value area, the q value detected by the 7 factors was between 0.009 and 0.034 . The selected factor cannot perfectly explain the source of $\mathrm{Hg}$, so the analysis was carried out from the perspective of the layout of factories and enterprises. The factories and enterprises in this area are densely distributed, and most are in high-polluting industries such as textile printing and dyeing, papermaking chemicals, machinery manufacturing, and non-ferrous metal synthesis. Highpolluting industries produce industrial "three wastes" with extremely high $\mathrm{Hg}$ content.

At present, there is no indicator that can directly and quantitatively reflect various types of enterprises to explain the source of $\mathrm{Hg}$, so the analysis is limited to the consistency of spatial distribution. $\mathrm{Hg}$ and its compounds were volatile in this region, allowing $\mathrm{Hg}$ to be transmitted over long distances. Thus, the $\mathrm{I}_{\text {geo }}$ low-value areas surrounded high-concentration 
areas, and non-polluted areas were in remote places. The heavy metal $\mathrm{Hg}$ content in areas with densely distributed high-polluting industries increased along with density and industry (as shown in Fig. 5b). These high-polluting industries were the main source of heavy metal Hg pollution in the area. This area is economically developed, so these pollution sources need to be treated to prevent harm to the health of residents.

\section{Acknowledgments}

This study was supported by the National Natural Science Foundation of China (Nos. 41301509).

\section{Conflict of Interest}

The authors declare no conflict of interest.

\section{References}

1. DHALIWAL S., SINGH J., TANEJA P.K., MANDAL A. Remediation techniques for removal of heavy metals from the soil contaminated through different sources: a review. Environmental Science and Pollution Research, 27 (2), 1319, 2020.

2. TSAI M.S., CHEN M.H., LIN C.C., LIU C.Y., CHEN P.C. Children's environmental health based on birth cohort studies of Asia (2) - air pollution, pesticides, and heavy metals. Environmental Research, 179, 108754, 2019.

3. HU H., JIN Q., KAVAN P. A study of heavy metal pollution in China: Current status, pollution-control policies and countermeasures. Sustainability (Switzerland), 6 (9), 5820, 2014.

4. CAI X.F., DUAN Z.B., WANG J. Status assessment, spatial distribution and health risk of heavy metals in agricultural soils around mining-impacted communities in China. Polish Journal of Environmental Studies, 30 (2), 993, 2021.

5. VAVERKOVA M.D., MAXIANOVA A., WINKLER J., ADAMEOVA D., PODLASEK A. Environmental consequences and the role of illegal waste dumps and their impact on land degradation. Land Use Policy, 89, 2019.

6. CAI L.M., XU Z.C., QI J.Y., FENG, Z.Z., XIANG T.S. Assessment of exposure to heavy metals and health risks among residents near Tonglushan mine in Hubei, China. Chemosphere, 127, 127, 2015.

7. NEMATOLLAHI M.J., KESHAVARZI B., ZAREMOAIEDI F., RAJABZADDH M.A., MOORE F. Ecological-health risk assessment and bioavailability of potentially toxic elements (PTEs) in soil and plant around a copper smelter. Environmental Monitoring and Assessment, 192 (10), 639, 2020.

8. WEI X.D., ZHOU Y.T., JIANG Y.J., TSANG D.C.W., ZHANG C.S., LIU J., ZHOU Y.C., YIN M.L., WANG J., SHEN N.P., XIAO T.F., CHEN Y.H. Health risks of metal(loid)s in maize (Zea mays L.) in an artisanal zinc smelting zone and source fingerprinting by lead isotope. Science of the Total Environment, 742, 140321, 2020.

9. PAN J.Y., LIN C.C., WU C.J., CHANG J.P. Early and intermediate-term results of the extracardiac conduit total cavopulmonary connection for functional single-ventricle hearts. Journal of the Formosan Medical Association, 115 (5), 318, 2016

10. BARGAGLI R., AGNORELLI C., BORGHINI F., MONACI F. Enhanced deposition and bioaccumulation of mercury in antarctic terrestrial ecosystems facing a coastal polynya. Environmental Science and Technology, 39 (21), 8150, 2005.

11. BORUVKA L., VACEK O., JEHLIEKA J. Principal component analysis as a tool to indicate the origin of potentially toxic elements in soils. Geoderma, 128 (3-4 SPEC. ISS.), 289, 2005.

12. ACOSTA J.A., FAZ A., MARTINEZ M.S. Identification of heavy metal sources by multivariable analysis in a typical Mediterranean city (SE Spain). Environmental Monitoring and Assessment, 169 (1-4), 519, 2010.

13. WANG J.F., ZHANG T.L., FU B.J. A measure of spatial stratified heterogeneity. Ecological Indicators, 67, 250, 2016.

14. GAO H.L., ZHANG TL., FAN H.Y., JIANG S.R., HUANG Y. Quantitative Analysis of the Factors Affecting Ecological Environment Quality in Yangling Demonstration Zone Based on Geographical Detector. Journal of Northwest Forestry University, 35 (5), 185, 2020.

15. YANG K.Y., SONG Y.Y., XUE D.Q. Spatiotemporal change of rural settlement land in the Loess Plateau and influencing factors. Resources Science, 42 (7), 1311, 2020.

16. JING Z.Y., LIU P.F., WANG T.H., SONG H.Q., LEE J., XU T., XING Y. Effects of meteorological factors and anthropogenic precursors on PM2.5 concentrations in cities in China. Sustainability (Switzerland), 12 (9), 1, 2020.

17. WU W.Q., ZHANG M., DING Y.T. Exploring the effect of economic and environment factors on PM2.5 concentration: A case study of the Beijing-Tianjin-Hebei region. Journal of Environmental Management, 268, 110703, 2020.

18. DING Y.T., ZHANG M., QIAN X.Y., LI, C.R., CHEN, S., WANG W.W. Using the geographical detector technique to explore the impact of socioeconomic factors on PM2.5 concentrations in China. Journal of Cleaner Production, 211, 1480, 2019.

19. JIANG Y.Y., SUN Y.J., ZHANG L.P., WANG X.L. Influence factor analysis of soil heavy metal $\mathrm{Cd}$ based on the GeoDetector. Stochastic Environmental Research and Risk Assessment, 34 (6), 921, 2020.

20. LI J.T., SUN Z.F. Urban Function Orientation Based on Spatiotemporal Differences and Driving Factors of Urban Construction Land. Journal of Urban Planning and Development, 146 (3), 05020011, 2020.

21. SHI T.Z., HU Z.W., SHI Z., GUO L., CHEN Y.Y., LI Q.Q., WU G.F. Geo-detection of factors controlling spatial patterns of heavy metals in urban topsoil using multisource data. Science of the Total Environment, 643, 451, 2018.

22. CHEN M.H., LIU W.F., WANG S., LIU Y.X. Spatial pattern and temporal trend of urban ecological efficiency in the Yangtze River Economic Belt. Resources Science, 42 (6), 1087, 2020.

23. WANG Z., CHEN X.M., YU D.Q., ZHANG L.X., WANG J.N., LV J.S. Source apportionment and spatial distribution of potentially toxic elements in soils: A new exploration on receptor and geostatistical models. Science of the Total Environment, 759, 143428, 2021. 
24. SHEN H.Y., AN R., SHI H.D., LIU X.Y., ZHANG A.D. Heavy Metal Pollution and its Influencing Factors in Agricultural land in a Typical Watershed in Hunan Province SHEN. Research of Environmental Sciences, 34 (3), 715, 2021.

25. SUN W.L., SANG L.X., JIANG B.F. Trace metals in sediments and aquatic plants from the Xiangjiang River, China. Journal of Soils and Sediments, 12 (10), 1649, 2012.

26. LUO Q.F., ZHANG J., JIANG L., LU C.J., GUO N., ZHANG Q.X., LI W.Y. Heavy metal concentrations and pollution assessment of riparian soils in Liaocheng City. Ecological Science, 36 (1), 209, 2017.

27. SALEH Y.S. Evaluation of sediment contamination in the Red Sea coastal area combining multiple pollution indices and multivariate statistical techniques. International Journal of Sediment Research, 36 (2), 243, 2021.

28. HAKANSON L. An ecological risk index for aquatic pollution control.a sedimentological approach. Water Research, 14 (8), 975, 1980.

29. WANG J.F., LI X.H., CHRISSTAKOS G., LIAO Y.L., ZHANG T., GU X., ZHENG X. Y. Geographical detectors-based health risk assessment and its application in the neural tube defects study of the Heshun Region, China. International Journal of Geographical Information Science, 24 (1), 107, 2010.

30. WANG J.F., XU C.D. Geodetector: Principle and prospective. Acta Geographica Sinica, 72 (1), 116, 2017.

31. FU C.C., WANG W.Y., PAN J.J., ZHANG W.M., ZHANG W., LIAO Q. A. Comparative Study on Different Soil
Heavy Metal Interpolation Methods in Lishui District, Nanjing. Chinese Journal of Soil Science, 45 (6), 1325, 2014.

32. LIU Y., MA Z.W., LV J.S., BI J. Identifying sources and hazardous risks of heavy metals in topsoils of rapidly urbanizing East China. Journal of Geographical Sciences, 26 (6), 735, 2016.

33. CAO F., GE Y., WANG J.F. Optimal discretization for geographical detectors-based risk assessment. GIScience and Remote Sensing, 50 (1), 78, 2013.

34. CHIKAMASA T., SHIBATA H., URAKAWA R., FUKUZAWA K., HIROBE M., INAGAKI Y. Spatial distribution of mercury accumulation in the surface soil of Japanese forests. Journal of Forest Research, 26 (2), 161, 2021.

35. QINN B.T., GE L.M. Relative environmental regulations, pollution-intensive industry transfer and pollution agglomeration in China. China population, resources and environment, 28 (12), 52, 2018.

36. JIA X.L., HU B.F., MARCHANT B.P., ZHOU L.Q., SHI Z., ZHU Y.W. A methodological framework for identifying potential sources of soil heavy metal pollution based on machine learning: A case study in the. Environmental Pollution, 250, 601, 2019.

37. ZHENG G.Z. Theory and Practice of Research on Heavy Metal Pollution in Agricultural Soil. Beijing: China Environmental Science Press, 5, 57, 2007. 